cardinal symptoms of a pharyngeal pouch also include spontaneous regurgitation, weight loss, and dysphagia.

Barium swallow is the principal means of diagnosing both oesophageal achalasia ${ }^{3}$ and pharyngeal pouch. Moreover, there is a very real risk of a traumatic oesophageal perforation as a result of entering an unknown pouch, even with a flexible endoscope. Barium swallow is a simple, non-traumatic, cheap, and safe outpatient investigation suitable for most patients with suspected oesophageal pathology, and traumatic oesophageal perforation due to endoscopy in the absence of a barium swallow would be difficult to defend.

A J PRIOR

Department of Otolaryngology

Whipps Cross Hospital,

London

1 Pagliero KM. Oesophageal achalasia mistaken for anorexia nervosa. BMF 1992;305:583. (5 September.)

2 Bowdler DA. Pharyngeal pouches. In: Kerr AG, ed. Scott-Brown's otolaryngology. Vol 5. 5th ed. Oxford: Butterworth Heinemann, 1987:264-83.

3 Phelps PD. Radiology of the pharynx and larynx. In: Kerr AG, ed. Scott-Brown's otolaryngology. Vol 5. 5th ed. Oxford: Butterworth Heinemann, 1987:7-30.

\section{Partners in practice}

EDITOR, - I was concerned to note the omission of the pharmacist from the spectrum of carers portrayed by Constance Martin, although she seemed to consider every possible lay and professional carer who might come into contact with the patient. ${ }^{1}$ I am a pharmacist employed as a lecturer within a university department of general practice and one of my research interests concerns the interface of pharmacists and general practitioners and their shared role in the effective and appropriate use of medicines. Recent government publications have endorsed an extended role for the community pharmacist, which would include among other things greater patient involvement and interdisciplinary collaboration with general practitioners. ${ }^{23}$

In the hospital setting the pharmacist plays an important and established part in decisions relating to the pharmaceutical care of patients. There is also a definite and equivalent place for the pharmacist in the primary health care team, and this should be acknowledged by the other professions so that the particular skills of the profession are utilised to the benefit of the rest of the team, and most importantly the patient.

CHRISTINE M BOND

Department of General Practice,

University of Aberdeen,

Foresterhill Health Centre,

Aberdeen AB9 2AY

1 Martin C. Partners in practice: attached, detached, or new recruits? BMF 1992;305:348-50. (8 August.)

2 Secretaries of State for Social Services, Wales, Northern Ireland and Scotland. Promoting better health. London: HMSO, 1987. (Cmnd 249.)

3 Department of Health Joint Working Party. Pharmaceutical care: the future for community pharmacy. London: Royal Pharmaceutical Society, 1992.

\section{Delays in thrombolysis}

EDIToR,-J S Birkhead's review of delays to thrombolysis in patients with suspected myocardial infarction ${ }^{1}$ raises some important issues with regard to the effective delivery of modern coronary care.

Firstly, now that the components of delay are reasonably well understood it is time to introduce systematic monitoring of the administration of these drugs. This could most easily be achieved by incorporating delay monitoring into the service specification of contracts for coronary care between purchasing authorities and their provider units Since only a portion of the total delay is the direct responsibility of the hospital service this would have to be broken down into delay between onset of symptoms and calling for help; delay between calling for help and arriving at hospital; and, finally, "door to needle" time. Each component of delay could then be tackled separately and the results of intervention continuously monitored.

Secondly, Birkhead expresses some concern that wider use of self referral to hospital through the ambulance service may lead to inappropriate calls. This is clearly a concern, but as over half of myocardial infarct victims already have established coronary heart disease ${ }^{2}$ this problem could be minimised by concentrating advice on self referral to people known to have heart disease or at high risk in the first instance.

Thirdly, the data presented in the review suggest that only $58 \%$ of patients later shown to have myocardial infarction received thrombolysis. The reasons for not giving thrombolytic drugs have been presented in a recent study from Edinburgh. ${ }^{3}$ These were non-diagnostic electrocardiogram $(46 \%)$; over six hours' delay since onset of symptoms (18\%); peptic ulcer (5\%); and "miscellaneous" $(31 \%)$. Since thrombolytics have such a dramatic effect on mortality an expansion in coverage as well as a reduction in delay is important. Now that delays in thrombolysis have been analysed perhaps it is time for clarification of a feasible target for thrombolytic coverage in patients with myocardial infarction.

PAUL WATSON

School of Public Health

University of Leeds,

Leeds LS2 9LN

Birkhead JS. Time delays in provision of thrombolytic treatment in six district hospitals. BM7 1992;305:445-8.

2 Armstrong A, Duncan B, Oliver MF, Julian DG, Donald KW, Fulton $M$, et al. Natural history of acute coronary attacks. Br Heart f 1972:34:67-80.

3 Pell CH, Miller HC, Robertson CE, Fox KAA. Effect of "fast track" admission for acute myocardial infarction on delay to thrombolysis. BMF 1992;304:83-6.

\section{False positive salivary HIV test}

EDITOR, - When asked to do an HIV antibody test for insurance, employment, or other, similar purposes I counsel the patient before sending the blood sample to my local public health laboratory. On receiving the result I give a copy of the report to my client and it is up to him or her to use this information in whatever way he or she chooses. I have always refused to send a specimen to a laboratory if I am not going to be informed of the outcome.

Recently a local general practitioner asked me to see a patient; he had been told that the patient was apparently HIV positive. The man required an HIV test for insurance purposes. After counselling by the general practitioner he was asked to produce a saliva specimen, which was dispatched to a named laboratory in a kit supplied by the insurance company. The patient subsequently received a verbal message to see his general practitioner, who had been informed of his HIV status. The insurance company suggested that the man should be given a blood test to check the result of the salivary test. There was nothing in the man's history to suggest that he had been at risk, and the result of the serological test for HIV antibodies was, as expected, negative.

Several disturbing points arise from this case. Firstly, this man, who was happily married with a family, suffered 48 hours of considerable distress, which in someone less well balanced could have led to attempted or even successful suicide. Secondly, although the insurance company assured the general practitioner that all information relating to the patient's original positive HIV test result would be eliminated from the records, what guarantee has the patient that this in fact has been done? Finally, I understand that the salivary test for HIV was developed as an epidemiological tool and in no way was to be a substitute for the serological test. The apparent false positive result of the salivary test must cast doubt on the quality control procedures of the laboratory that performed that inappropriate test.

DELIA F MORRIS

Department of Genitourinary Medicine,

Burton District Hospital Centre,

Burton on Trent,

Staffordshire DE13 ORB

\section{Preparing for a foreign fellow}

EDITOR,-Lindsay J Smith and Catherine Marraffa's advice to those preparing for a foreign fellow requires expansion to cater for the position of overseas qualified doctors who are not registered with the General Medical Council before they arrive in Britain.' Not all primary medical degrees granted overseas are accepted by the council for registration. Many more degrees are accepted for limited than for full registration, and the range of employment open to doctors holding such degrees is limited accordingly.

The granting of limited registration is in addition subject to several statutory conditions, and scrutinising applications is a complex task that takes time. The council advises all overseas qualified doctors planning to come to Britain to get in touch with the council's overseas registration division at least six months before their intended arrival to obtain advice about their eligibility.

Doctors who are eligible for registration must submit the originals of their degrees and other certificates: the council does not accept any kind of copy, including the notarised copies to which Smith and Marraffa refer.

General Medical Council

P L TOWERS London WIN $6 \mathrm{AE}$

1 Smith LJ, Morraffa C. How to prepare for a foreign fellow. BMf 1992;305:460-1. (22 August.)

\section{Psychiatrists in the new NHS}

EDIToR,-By April 1993 there will be about 6500 fundholding general practitioners. From the same date, general practitioner fundholders will purchase for their patients all community and outpatient mental health services. ' What will this mean for psychiatry?

To predict how fundholding general practitioners might wield these new powers we need to look at how they use and what they say about mental health services now. General practitioners increasingly refer patients to the growing numbers of community psychiatric nurses, clinical psychologists, and counsellors, and when these options are available the number of referrals to psychiatry services are almost certain to fall. ${ }^{2}$

Are these other professionals as effective as psychiatrists? A recently published randomised trial of care for depressed patients in primary care found counselling (in this case by a social worker) to be significantly more effective clinically, more likely to be endorsed by patients, and as cost effective as treatment by a psychiatrist. ${ }^{3}$ Other studies have shown other specialist or paramedical staff to be at least as effective as psychiatrists. ${ }^{+}$

The challenge to psychiatry posed by the growth of other professions is not new. Ten years ago Michael Shepherd warned that "the psychiatrist must now be prepared to define his own function if he is to justify his status." General practitioner fundholding and the internal market, however, are crucial new factors in the equation. If the NHS reforms continue in the intended direction there will be a large transfer of resources and power from 